\title{
LA DEFENSA DIRECTA DE LA AUTONOMIA LOCAL ANTE EL TRIBUNAL CONSTITUCIONAL *
}

\author{
POR \\ JAVIER SALAS \\ Catedrático de Derecho Administrativo \\ en la Universidad Complutense
}

La presente ponencia se enmarca dentro del cuadro más amplio de la defensa jurisdiccional de la autonomía local. Dado que hay otra ponencia, que se encuadra también dentro de esta temática, concretamente la del Profesor Gómez Ferrer, que trata de las vías indirectas de acceso a la Justicia constitucional, la mía la centraré en la defensa directa de esa autonomía ante el Tribunal Constitucional.

El presupuesto de cuanto voy a decir aqui sobre las diferentes vías de acceso al Tribunal Constitucional es la autonomía local como garantía institucional, reconocida expresamente, como saben, en los artículos 137, 140 y 141 de la Carta fundamental.

Dando por sentado lo que sea la autonomía local, voy a abordar aquí los aspectos procesales del tema, la garantía de este principio ante la jurisdicción constitucional. Me remito, pues, a lo que en la doctrina y en la propia jurisprudencia del Tribunal Constitucional se ha dicho sobre el contenido y los límites de la autonomía local, es decir, dejo al margen todo lo relativo al aspecto sustantivo o material de la cuestión. Ahí están, en efecto, especialmente, las Sentencias del Tribunal Constitucional 4/1981, Legislación de régimen local, y 32/1981, Ley de las Diputaciones catalanas, en la que se desarrolla con cierta amplitud la institución de la autonomía local como garantía institucional.

Dicho esto, comenzaré por hacer referencia al recurso de inconstitucionalidad contra normas con valor de ley.

Como saben, la Constitución [art. 162.1.a)] ha limitado taxativamente el número de sujetos legitimados para interponer este tipo de recurso ante el Tribunal Constitucional, limitación ésta a la que se refiere la Sentencia 6/1986, que señala que la Ley Orgánica del Tribunal Constitucional (en adelante LOTC) regula en su artículo 32 la legitimación de forma limitada. En la misma línea cabe citar el Auto 33/1986, que reitera jurisprudencia anterior -entre la que destaca el Auto 387/1982-, según la cual el sentido de la regulación legal en este punto es el de delimitar con carácter

- Ponencia presentada en las Jornadas sobre «Administració Local i Adrministració de Justician celebradas en Barcelona del 20 al 22 de septiembre de 1988. 
general a los legitimados para interponer el recurso y personarse en el correspondiente proceso, por lo que no es posible admitirá como parte a otras personas cuyos intereses están protegidos por el ordenamiento a través de otros medios, como la impugnación de los actos de aplicación. Se trata, pues, de una legitimación upor atribución constitucional», no de una legitimación por interés, como es habitual en los procesos ante la jurisdicción ordinaria (salvo los supuestos de acción pública o popular).

Quizá se pregunten ustedes que qué «interés» puede tener para interponer un recurso de inconstitucionalidad por una presunta vulneración de la autonomía local por una Ley del Estado, por ejemplo, el Presidente del Gobierno o la minoría parlamentaria o incluso una Comunidad Autónoma, cuando la Ley que presuntamente vulnere la autonomía local sea precisamente emanación del Parlamento de esa misma Comunidad Autónoma.

Cabe, ciertamente, la posibilidad de acceder al Defensor del Pueblo para que interponga el recurso en cuestión. Ahora bien, ni el Defensor del Pueblo ni ninguno de los demás órganos a los que se ha hecho referencia queda vinculado por tal solicitud. A este respecto hay que señalar que existen dos autos del Tribunal Constitucional en los que se niega expresamente la legitimación para interponer recurso de inconstitucionalidad a un ente local, aunque se trate, como es el caso del País Vasco, de un Territorio Histórico, concretamente la Diputación Foral de Vizcaya.

Así, en el Auto 1021/1987, de 22 de septiembre, recaído en el recurso de inconstitucionalidad 975/1987, en el que dicha Diputación Foral impugna la Ley vasca 1/1987, de elecciones para las Juntas Generales de los Territorios Históricos de Alava, Vizcaya y Guipúzcoa, el Tribunal Constitucional, tras señalar que upese al esfuerzo dialéctico que se muestra en la demanda, el presente recurso no puede admitirse a trámite debido a la falta de legitimación de la Diputación Foral de Vizcaya para interponer recurso de inconstitucionalidad", declara que "frente a lo que sostiene la Diputación Foral, no existe un correlato necesario entre garantía constitucional de derechos o de cualesquiera competencias (directa o indirecta a través de reconocimiento estatutario en lo que respecta a las Comunidades Autónomas o los territorios forales) y legitimación para interponer el recurso de inconstitucionalidad que se atribuye en enumeración cerrada por el artículo 162.1.a) de la Constitución y es reiterada en el artículo 32 de la LOTC». Así-sigue diciendo el Tribunal-, ula garantía constitucional y estatutaria de un ámbito competencial propio de los territorios forales no implica que éstos hayan de ostentar la legitimación para interponer recursos de inconstitucionalidad o conflictos de competencia». El Tribunal 
Constitucional distingue, pues, claramente el aspecto sustantivo del aspecto procesal a efectos de garantizar el primero. No hay necesariamente coincidencia entre el titular de ese ámbito competencial o de ese principio reconocido por la Constitución, de esa garantía institucional que es la autonomía local, con el sujeto que, ante una posible lesión de la misma, puede personarse en defensa de ella ante dicho Tribunal.

Según el Tribunal Constitucional, la interpretación que propone la recurrente del inciso final del artículo 162.1.a) de la Constitución no es admisible, ya que «de la tramitación parlamentaria durante la elaboración de la Constitución se deduce, sin género de dudas, que el inciso en cuestión hacía referencia, en exclusiva, a las instituciones generales de autogobierno de las Comunidades Autónomas, sin que se considerase excepción alguna en relación con el País Vasco y los territorios forales». De lo que concluye a continuación que «tanto los propios términos del inciso como su interpretación en el marco del Título VIII de la Constitución hacen inviable la pretensión de ampliar su ámbito a las instituciones propias de los territorios forales».

El Auto que acabamos de citar será recurrido en súplica por la Diputación Foral de Vizcaya, que no se conformó con la decisión y trató de rebatir los argumentos del Tribunal para que éste revisara la inadmisión del pretendido recurso de inconstitucionalidad. El Tribunal, por Auto 1142/1987, de 14 de octubre, rechazará, como era de esperar, dicho recurso de súplica de la Diputación Foral, reiterando la falta de legitimación de la misma para interponer recursos de inconstitucionalidad por las razones ya expuestas en el auto anterior, señalando que esto no implica unegar que la garantía de tales derechos pueda alcanzarse por otras vías procesales, sino que en el caso de autos el acceso directo a la jurisdicción constitucional requiere inevitablemente la actuación de quienes reciben la legitimación necesaria para ello de la Constitución y de la Ley Orgánica de este Tribunal». $Y$ añade -saliendo, sin duda, al paso de lo que está a la base de la argumentación de la recurrenteque «por muy criticable que la solución vigente pueda parecer a la entidad actora, la Constitución no atribuye a los órganos forales del País Vasco legitimación para interponer recurso de inconstitucionalidad», lo que, por lo demás $-y$ es significativo hacerlo notar en el marco de estas Jornadas-, «no es insólito, por cuanto la Constitución ofrece supuestos análogos: baste considerar, entre otros posibles ejemplos, que si bien los Ayuntamientos gozan de una garantía institucional de su autonomía (art. 140 de la Constitución), tampoco ostentan legitimación para interponer recursos de inconstitucionalidad». 
En otro fundamento jurídico del mismo Auto el Tribunal insiste en que "cuando el artículo 162.1.a) de la Constitución habla de los órganos colegiados ejecutivos de las Comunidades Autónomas y. en su caso, las Asambleas de las mismas, se refiere a órganos de autogobierno de las propias Comunidades Autónomas en cuanto tales y no de cualquier otra entidad territorial que integre o forme parte de aquéllas, como es el caso de los Territorios Históricos de la Comunidad Autónoma del País Vasco». Y para reforzar toda esta argumentación el auto por el que se resuelve ese recurso de súplica señala que «la apelación que se hace al permanente esfuerzo de este Tribunal por obviar innecesarios obstáculos procesales al acceso a la jurisdicción constitucional no puede ser atendida, ya que dicho esfuerzo tiene el límite infranqueable de los términos constitucionales y de su Ley Orgánica» y que "ningún esfuerzo interpretativo puede desvirtuar las consideraciones que se hicieron en el Auto impugnado y que se reiteran en los anteriores fundamentos jurídicos».

He querido insistir con un cierto detalle en la exposición de los principales argumentos contenidos en los fundamentos jurídicos de los autos citados porque creo que convenía remarcar la doctrina existente sobre este punto, precisamente, al tratar el tema de la legitimación para interponer recurso de inconstitucionalidad.

En relación con las cuestiones de inconstitucionalidad, es de notar que, de acuerdo con la Constitución (art. 163), los únicos sujetos legitimados para plantearlas son los órganos judiciales $y$, además, en el recurso de procesos sustanciados ante los mismos. No voy a entretenerme aquí en la descripción de la regulación de tales cuestiones de la LOTC ni en los presupuestos y requisitos necesarios para su planteamiento, sobre los que hay una abundante jurisprudencia del Tribunal Constitucional.

Imaginemos, sin embargo, que en el curso de un proceso concreto en el que una Corporación Local sea parte -lo cual no es infrecuente, especialmente en la vía contencioso-administrativa-, se suscita una cuestión sobre una norma legal -del Estado o de una Comunidad Autónoma- aplicable al caso que, por ejemplo, vulnera la garantía constitucionalmente garantizada de la autonomía local. La entidad local sólo puede suscitar ante el órgano judicial la cuestión, al igual que la otra parte, por lo demás; pero el órgano judicial no queda vinculado, como saben, por esta solicitud y puede rechazar el planteamiento de la misma. En este sentido, existe una jurisprudencia reiterada del Tribunal Constitucional en la que se insiste que el rechazo del planteamiento de una cuestión de inconstitucionalidad no constituye vulneración del derecho a la tutela judicial efectiva. 
Por otro lado, al igual que las partes del proceso en el que se ha planteado una cuestión de inconstitucionalidad no pueden comparecer, con carácter general, ante el Tribunal Constitucional, tampoco puede personarse ante el mismo la entidad local parte en el proceso a quo para argumentar a favor de la presunta inconstitucionalidad de la Ley cuestionada por vulneración, en este caso, de la autonomía local.

La doctrina expuesta puede verse, entre otras resoluciones, en el Auto 18/1983, así como en la Sentencia 133/1987, según la cual en el artículo 35 de la LOTC, que regula la cuestión de inconstitucionalidad, no se contiene un recurso a disposición de las partes de un proceso, pues la referida cuestión es un medio de asegurar la supremacía de la Constitución, que corresponde en forma exclusiva al órgano judicial. En definitiva, como con toda rotundidad ha señalado el Auto 309/1987, sólo pueden comparecer los órganos a que se refiere el artículo 37 de la LOTC, de modo que quedan excluidos del proceso cualesquiera otras personas físicas o jurídicas, cualesquiera que fuesen los intereses que tengan en el mantenimiento o en la invalidación de la Ley o de los actos realizados en aplicación de la misma, regla aplicable no sólo a la fase de cognición previa a la sentencia, sino también una vez que ésta se ha dictado.

Precisión esta última significativa porque dicho Auto va a resolver una solicitud formulada precisamente por la Federación de Municipios de Cataluña para comparecer en el incidente de ejecución de la Sentencia del Tribunal Constitucional 19/1987, que resuelve la cuestión de inconstitucionalidad, relativa al artículo 13.1 de la Ley 24/1983, de medidas urgentes de saneamiento $y$ regulación de las Haciendas Locales.

Pues bien, dicha Federación se persona en el Tribunal Constitucional y solicita que se la tenga como parte en la fase de ejecución de esta sentencia $y$, subsidiariamente, que se emita aclaración de la misma, habida cuenta de la trascendencia de las cuestiones planteadas. A los argumentos por los cuales entiende que puede personarse en esta fase de ejecución, a los que se oponen el Fiscal general del Estado y el Letrado del Estado -a los que se ha dado traslado de tal pretensión-, el Tribunal responde con el razonamiento basado en la doctrina general a que acabo de referirme $y$ añade que las Sentencias declaratorias de inconstitucionalidad de las Leyes, que determinan el efecto de invalidación de las mismas, no tienen ejecución por la justicia constitucional, producen efectos generales y vinculan a todos los poderes públicos, como dice el artículo 38 de la LOTC, pero no requieren una especial actividad de ejecución por parte del Tribunal, sin que, por lo demás, sea posible 
solicitar genéricamente la aclaración de la Sentencia, pues la aclaración a que se refiere el artículo 93 de la LOTC sólo versa sobre conceptos oscuros comprendidos en el fallo o sobre omisiones del mismo que tengan por objeto puntos anteriormente discutidos en el litigio.

Esta doctrina constitucional, extraída de la propia configuración de la cuestión de inconstitucionalidad en la Constitución y en la LOTC, contrasta con la posibilidad de comparecencia, expresamente prevista en el artículo 37.2 de la LOTC, de las Comunidades Autónomas, que pueden personarse en las cuestiones de inconstitucionalidad que afecten a normas con fuerza de ley dictadas por las mismas. No. en las que afecten a normas legales dictadas por el Estado, por mucho que en ellas esté subyacente un litigio competencial. Así lo ha entendido, en efecto, el Tribunal Constitucional en el Auto 172/1986, que inadmite la personación del Consejo Ejecutivo de la Generalidad de Cataluña en la cuestión de inconstitucionalidad sobre el artículo 3.2 de la Ley 2/1984, de Colegios Profesionales.

Pues bien, la pregunta que cabe suscitar ahora, que tiene interés en el marco de esta ponencia, es si los entes locales pueden comparecer no ya como partes principales -que ya hemos visto que no-, sino como coadyuvantes, en los procesos de inconstitucionalidad (recursos y cuestiones).

La respuesta es que tampoco cabe esta posibilidad de coadyuvancia por parte de los entes locales en estos procesos, tal como se deduce de la doctrina, reiterada, por lo demás, del Tribunal Constitucional. Hay, en efecto, una serie de Autos desde uno, ya antiguo, el 124/1981, pasando por otros, el 387/1982 y el 132/1983, para llegar a los más recientes, el $1.203 / 1987$ y el $298 / 1988$. Ya en el primeramente citado se señala que es claro que en el artículo 81 de la LOTC no hay una generalización de los coadyuvantes, pues éstos no caben en el recurso directo de inconstitucionalidad, ni en la cuestión de inconstitucionalidad, que dicho precepto directamente sólo resuelve un problema de postulación, sin disponer nada sobre articulación de formas liticonsorciales o intervención de coadyuvantes. En el Auto 387/1982 se insiste en que no cabe la figura de la coadyuvancia en el recurso de inconstitucionalidad y que quienes no están legitimados para recurrir tampoco lo están para comparecer como coadyuvantes. En el Auto 132/1983 -que resuelve, inadmitiéndola, la solicitud para comparecer como coadyuvante del Consejo General de Colegios Oficiales de Farmacéuticos en la cuesión de inconstitucionalidad sobre la base XVI, párrafo noveno, de la Ley de 25 de noviembre de 1944, de Bases de Sanidad Nacional-, se reitera esta misma 
doctrina, añadiendo que con ello no se crea una situación de indefensión para personas cuyos intereses puedan verse afectados por la Sentencia del Tribunal Constitucional, que es resultado de un proceso estrictamente objetivo, en el que en ningún caso pueden hacerse valer derechos subjetivos o intereses legitimos.

Por lo que respecta a los dos Autos más recientes, es de destacar que en el 1.203/1987, que tiene en su base la pretensión de un funcionario de la Comunidad Autónoma de Canarias de comparecer como coadyuvante en un recurso de inconstitucionalidad promovido por el Presidente del Gobierno de la Nación contra la Ley canaria de la Función Pública, el Tribunal Constitucional negará esta posibilidad de personación, insistiendo en la doctrina a la que se ha hecho referencia. En el Auto 298/1988 se niega la personación como coadyuvante de la Junta de Extremadura en la cuestión de inconstitucionalidad planteada por la Sala de lo Contencioso-Administrativo de la Audiencia Territorial de Cáceres sobre el artículo 6.2 de la Ley 34/1979, de Fincas Manifiestamente Mejorables, insistiéndose de nuevo que sólo están legitimados para comparecer los órganos taxativamente enumerados en el artículo 37.2 de la LOTC y en que ello no supone indefensión para las personas físicas o juridicas cuyos intereses puedan ser afectados por la Sentencia del Tribunal Constitucional.

A la vista de cuanto acaba de exponerse, la conclusión no puede ser otra que la negación de la posibilidad de defensa directa de la autonomía local por parte de las Corporaciones Locales en los procesos de inconstitucionalidad.

Hay, sin embargo, una vía, aunque muy limitada, prevista en el artículo 119 de la Ley 7/1985, reguladora de las Bases del Régimen Local, según el cual la Comisión Nacional de Administración Local podrá solicitar de los órganos constitucionalmente legitimados para ello la impugnación ante el Tribunal Constitucional de las leyes del Estado o de las Comunidades Autónomas que estime lesivas para la autonomía local garantizada constitucionalmente, solicitud ésta -añade el mismo precepto- que podrá realizarla la representación de las entidades locales en la citada Comisión.

No cabe duda, sin embargo, que cuando se trate de una Ley del Estado será realmente difícil que la Comisión como tal tome la iniciativa aludida, habida cuenta de que la misma se compone paritariamente de representantes de la Administración del Estado y de las entidades locales y que sus acuerdos, según establece el artículo 117.3 de la misma Ley, deben adoptarse "por consenso entre ambas representaciones». Es evidente que no va a ser fácil lograr ese consenso de los representantes de la Administración del Estado para impugnar una ley aprobada por las Cortes Generales. 
Ciertamente, la solicitud puede hacerla también, como hemos visto, la representación de las entidades locales en la Comisión, es decir, una de las dos partes que integran la Comisión Nacional de la Administración Local. Ahora bien, en este caso, en el que el acuerdo de las entidades locales se obtiene por mayoría absoluta de sus miembros, queda ya un tanto debilitada la "fuerza» de la solicitud en cuestión, en la medida en que sólo una de las partes representadas en la Comisión, concretamente la de las entidades locales, la formula. Sin que pueda olvidarse, por lo demás, que se trata simplemente de una mera "solicitud" que no vincula a los órganos legitimados para interponer el recurso de inconstitucionalidad, es decir, al Gobierno o, mejor dicho, al Presidente del mismo, ni a la minoría parlamentaria, ni al Defensor del Pueblo, ni a los Gobiernos o los Parlamentos de las Comunidades Autónomas a los que se dirija dicha solicitud.

Veamos a continuación otra posible vía de defensa de la autonomía local ante el Tribunal Constitucional, en concreto la de los conflictos de competencia. En este caso, la LOTC (art. 60) establece que sujetos legitimados para plantearlos son el Gobierno de la Nación y los órganos colegiados ejecutivos de las Comunidades Autónomas. Tampoco aquí, por tanto, pueden comparecer como sujetos principales los entes locales. Los conflictos de competencia sólo pueden suscitarse, como ha declarado con todo énfasis la Sentencia 11/1984, Deuda pública vasca, entre el Estado y las Comunidades Autónomas, en modo alguno entre Estado y entidades locales (los Territorios Históricos del País Vasco, en el caso). Es de notar, sin embargo, que, a diferencia de lo que hemos visto que ocurre en los procesos de inconstitucionalidad, en los conflictos de competencia es posible que comparezcan como coadyuvantes de las partes principales en conflicto otros sujetos interesados. Posibilidad ésta que el Tribunal Constitucional ha admitido, desde el principio, con carácter general.

Así el Auto 124/1981 señala que la legitimación de los coadyuvantes tiene que fundarse en un interés y esta situación jurídica puede resultar afectada por la resolución que se dicte en el proceso y cita a este respecto los artículos 65 y 66 de la LOTC, que funcionan, respecto a los actos administrativos concretos, como un proceso constitucional administrativo abreviado, en el que es posible la intervención de coadyuvantes.

Esta doctrina temprana, como he dicho, será reiterada con posterioridad, y así, en el Auto 459/1985 se dice que, si bien la figura del coadyuvante no se encuentra prevista en la regulación de los conflictos de competencia entre el Estado y las Comunidades 
Autónomas, en los que el debate de las titularidades de las competencias afecta exclusivamente a los intereses públicos de que uno y otras son titulares, la intervención de coadyuvantes puede admitirse en aquellos casos en que, de acuerdo con el artículo 66 de la LOTC, en el proceso constitucional, además de la titularidad de la competencia, haya que decidir sobre actos y situaciones de hecho o de derecho creadas por el acto determinante del conflicto, en las que existan intereses concretos $y$ directos de terceras personas.

Esta doctrina, sin embargo -añade el Tribunal-, no autoriza para retrotraer las actuaciones a un momento anterior a aquel en que se encuentran, con lo cual puede ocurrir que al que comparece, y le es admitida la comparecencia como coadyuvante, pueda quedar en el proceso como un simple "convidado de piedra», si resulta que se han hecho ya las alegaciones oportunas y está sólo pendiente de señalamiento para deliberación y fallo el conflicto de que se trate.

En el asunto a que se refiere el Auto 459/1985, se admite como coadyuvantes a una confederación empresarial y a dos sindicatos en un conflicto de competencia planteado entre el Estado y la Comunidad Autónoma vasca, en relación con un acuerdo del Pleno del Consejo de Relaciones Laborales de la Comunidad vasca sobre resolución de conflictos colectivos y negociación colectiva, suscrito precisamente entre los sindicatos y la confederación empresarial citados, que serán justamente los que van a tratar de comparecer como coadyuvantes en ese conflicto, en el que el Tribunal Constitucional va a admitir su comparecencia. Por tanto, en base a esta doctrina general, entiendo que es posible admitir la coadyuvancia de las Corporaciones Locales interesadas en los conflictos de competencia trabados entre el Estado y las Comunidades Autónomas.

La doctrina expuesta se reitera luego, con carácter general, en el Auto 173/1986, recaído en un conflicto entre el Estado y el País Vasco sobre una resolución relativa a provisión de plazas de maestros en esta Comunidad Autónoma, aunque en este caso niega la legitimación para comparecer en el mismo como coadyuvantes a determinadas personas particulares, por entender el Tribunal que no se trata de decidir, en este supuesto concreto, sobre actos o situaciones de hecho o de derecho creados por el acto determinante del conflicto, sino, mucho más abstractamente, de pronunciarse sobre la titularidad de la competencia, sin afectar de modo directo a derechos o situaciones ya surgidos, sino solamente a meras expectativas de una pluralidad de personas en su condición de simples aspirantes a las plazas en cuestión. 
En definitiva, sólo cabe la coadyuvancia, incluida, por supuesto, la•de los entes locales, siempre que haya unas situaciones de hecho o de derecho que se vean afectadas por la resolución del conflicto y que, en nuestro caso, afecten al ámbito competencial de las Corporaciones Locales.

Destacaré aqui, por último, por su interés en este foro, el Auto $55 / 1988$, recaído en un conflicto de competencia frente al Estado planteado por el Consejo Ejecutivo de la Generalidad de Cataluña en relación con un convenio concertado entre la Dirección General de la Vivienda, del Ministerio de Obras Públicas y Urbanismo y el Patronato Municipal de la Vivienda del Ayuntamiento de Barcelona. Pues bien, en este Auto, en el que se reitera la doctrina establecida en las resoluciones citadas, se insiste en que si bien la figura del coadyuvante no se encuentra prevista en relación con los conflictos de competencia entre el Estado y la Comunidad Autónoma, en los que el debate de la titularidad de la competencia controvertida afecta exclusivamente a los intereses públicos de uno y otras, la intervención de coadyuvantes puede admitirse en aquellos casos en que, de acuerdo con lo dispuesto en el artículo 66 de la LOTC en el proceso constitucional haya que decidir además sobre actos y situaciones de hecho o de derecho creados por el acto determinante del conflicto en los que existan intereses concretos y directos de terceros que pretenden comparecer como tales coadyuvantes.

Con la aludida reserva se reconoce, pues, expresamente la posibilidad de comparecencia como coadyuvante en un conflicto trabado entre el Estado y una Comunidad Autónoma, de un Ayuntamiento.

El recurso de amparo sería la cuarta y última vía a tener en cuenta. Este recurso está previsto, como se sabe, en el artículo 53.2 de la Carta Fundamental, siendo su finalidad obtener la tutela de las libertades públicas y derechos fundamentales reconocidos en el artículo 14 y demás preceptos comprendidos en la sección primera del capítulo segundo del título I de la Constitución, es decir, en los artículos 15 a 29, así como el derecho a la objeción de conciencia, reconocido en el artículo 30.2.

Pues bien, habida cuenta que la autonomía local no se encuentra en ese catálogo de derechos y libertades que tienen garantizada la posibilidad de acceso, mediante el recurso de amparo, ante el Tribunal Constitucional, debe negarse rotundamente que dicha autonomía pueda garantizarse constitucionalmente a través del recurso de amparo.

¿Qué ocurre entonces ante una posible vulneración de esta autonomía? Pues sencillamente, insistimos, que no puede garanti- 
zarse jurisdiccionalmente ante el Tribunal Constitucional a través del recurso de amparo. A este respecto existe una jurisprudencia constitucional reiterada desde el comienzo, concretamente desde el Auto 21/1980, en el que se señala que el artículo 137 de la Constitución y el principio de autonomía de las Corporaciones Locales no forman parte del ámbito susceptible de amparo constitucional.

En esta misma línea insistirán después, entre otros varios, los Autos 269/1983 y 603/1984. En el del año 1983 se dice que la vulneración de la autonomía municipal no puede remediarse a través del recurso de amparo, que a diferencia de otros sistemas jurídicos, no está abierto a los municipios para la defensa de su autonomía, sino sólo a los ciudadanos para la protección de los derechos fundamentales, y en el del 1984 se señala también, con toda rotundidad, que es claro que las suspuestas violaciones de los principios y derechos relativos a la autonomía local no son invocables en vía de amparo.

Quisiera destacar aquí, a este respecto, por su indudable interés, el Auto 269/1983, en el que precisamente fue parte en el recurso el Ayuntamiento de Barcelona. Se trata de un asunto de recaudación, en relación con el cual interviene uno de los Juzgados de Distrito de Barcelona y el Ayuntamiento, que es parte en el proceso judicial ordinario, interponer primero un recurso de reposición, después un recurso de apelación, que son desestimados, y contra estas resoluciones judiciales la Corporación Local interpone recurso de amparo ante el Tribunal Constitucional. Pues bien, hay, en primer lugar, una providencia del Tribunal en la que se ponen de manifiesto una serie de causas de inadmisión, entre otras, la de que no se trata, en este supuesto, de ventilar cuestiones relativas a derechos fundamentales. Se da audiencia para alegaciones sobre estos motivos de inadmisión al recurrente, Ayuntamiento de Barcelona, y al Ministerio Fiscal, y el primero argumenta entonces por primera vez - pues no lo había hecho en la demanda- que el Auto judicial impugnado viola el artículo 140 de la Constitución que garantiza la autonomía jurídica plena de los municipios, que esa infracción es directa e inmediatamente imputable al acto, en este caso del órgano judicial, y que, en consecuencia -dice el Ayuntamiento-, mal puede decirse que la demanda adolece del defecto puesto de relieve en la providencia. El Fiscal, por su parte, se opone a la admisión del recurso por entender que no se está ventilando una cuestión relativa a derechos fundamentales, y el Tribunal Constitucional, tajantemente, en un único fundamento jurídico, tras indicar que como se señalaba en la providencia y subraya el Ministerio Fiscal, la demanda que inicia el presente recurso no alega 
vịolación de ninguno de los derechos para cuya protección ha creado la Constitución la vía del amparo constitucional, añade que aunque en su escrito de alegaciones afirma el recurrente que el Auto judicial vulnera la autonomía municipal, que garantiza el artículo 140 de la Constitución, es cuestión en la que no puede entrarse, ni tampoco esa vulneración podría ser remediada a través del recurso de amparo, que, a diferencia de lo que ocurre en otros sistemas jurídicos que conocen recursos del mismo género, no está abierto a los municipios para la defensa de su autonomía, sino sólo a los ciudadanos para la protección de los derechos fundamentales ya mencionados.

El Tribunal Constitucional rechaza, pues, rotundamente, la posibilidad de utilización de la vía de amparo para articular a través de la misma la defensa frente a una presunta vulneración de la autonomía local.

Digamos, para terminar con este punto, que en la Sentencia 26/1987, que resuelve el recurso contra la Ley de Reforma Universitaria, se distingue con toda claridad entre garantía institucional $y$ derecho fundamental y se declara que si bien tales categorías jurídicas no son incompatibles entre sí ni se excluyen necesariamente, ya que buena parte de los derechos fundamentales que la Constitución reconoce constituyen también garantías institucionales, existen $-y$ esto es importante notarlo aquí a los efectos que estamos tratando-garantías institucionales que, como la autonomía local, no están configuradas como derechos fundamentales.

Señalaré dos cosas para finalizar ya esta ponencia: Una, que la doctrina, ante este panorama, realmente sombrío, si ustedes quieren, para la defensa de la autonomía local ante el Tribunal Constitucional, se ha esforzado por abrir algunos cauces a este respecto, $y$ ahí tenemos, por ejemplo, el significativo trabajo, pionero en este sentido, del profesor Martín Mateo, en su colaboración en las jornadas organizadas por la Dirección General de lo Contencioso del Estado sobre el Tribunal Constitucional. Este autor sostenía entonces la posibilidad de conexión de la autonomía local con algunos derechos fundamentales y que, en la medida en que tal conexión existiese en los supuestos concretos, podía defenderse dicha autonomía a través del recurso de amparo. Así, el Rector de la Universidad de Alicante hablaba de la posible conexión entre autonomía local e igualdad ante la ley, autonomía local y libertad ideológica de individuos y comunidades, autonomía local y derechos a participar en los asuntos públicos, a asociarse $o$ a acceder en condiciones de igualdad a las funciones y cargos públicos. Yo me permito dudar, sin embargo, de esas posibles conexiones que 
están, a mi juicio, en extremo forzadas, y entiendo, en consecuencia, que la posición sostenida por dicho autor es un tanto voluntarista.

¿Podría, pues, concluirse que está cerrado constitucionalmente todo acceso directo de los entes locales ante el Tribunal Constitucional en defensa de su autonomía? Aunque pueda parecer lo contrario de la exposición que acabo de hacer, no lo creo asi, y entiendo que cabe alguna posibilidad, aunque la vía en cuestión pueda ser todo lo limitada que ustedes quieran, y ello sin necesidad de reformar la Constitución, como ocurrió en la República Federal de Alemania en 1969, donde se estableció el recurso de queja constitucional para garantizar la autonomía local de municipios y mancomunidades de los mismos [art. 91.4.b)].

En el caso de Alemania se trata -nótese bien- de un recurso que puede interponerse por los entes locales en defensa de su autonomía, incluso contra leyes que vulneren ésta, leyes que normalmente serán de los Länder, que son los competentes en materia de régimen local, y del que conocerá no el Tribunal Constitucional Federal, sino el Tribunal Constitucional del correspondiente Länd, recurso que aquí no cabría sin reformar igualmente la Constitución.

La posibilidad a la que me refería es, sin embargo, otra, basada en la cláusula residual de competencia del Tribunal Constitucional, consagrada en el artículo 161.1.d) de la Carta fundamental, según el cual dicho Tribunal, además del recurso de inconstitucionalidad, del recurso de amparo y de los conflictos de competencia, puede conocer de las demảs materias que le atribuyan la Constitución o las leyes orgánicas. En este sentido, cabría, pues, la posibilidad de que una ley orgánica habilitara a los entes locales o a federaciones de los mismos a interponer ante el Tribunal Constitucional recursos no contra leyes, porque habría que modificar, como he dicho, la Constitución, dado que en ésta se halla tasada la lista de sujetos legitimados para interponer recursos de inconstitucionalidad, sino contra disposiciones reglamentarias y resoluciones administrativas que vulnerasen la autonomía local.

Claro es que entonces ustedes se preguntarán que para eso ya están los Tribunales de lo Contencioso-Administrativo, y es verdad. Lo que ocurre es que de esta manera la jurisdicción estaria concentrada, sin perjuicio de que el recurso aludido fuera subsidiario, de modo que el Tribunal Constitucional llegara a conocer de estas posibles vulneraciones de la autonomía local, que, como tales, hoy por hoy, no son directamente residenciables por los entes locales ante el mismo. 
Como habrán podido ver, he hecho una exposición del estado del tema objeto de la presente ponencia a la luz de la Constitución y de la LOTC, así como de la jurisprudencia del Tribunal Constitucional, para finalizar con una posible solución que, lo reconozco, no parece que colme las expectativas de quienes buscan afanosamente nuevas vías directas de protección constitucional de la autonomía local. 